\title{
Association between epilepsy and attempted suicide
}

\author{
KEITH HAWTON, JOAN FAGG, AND PAMELA MARSACK \\ From the University Department of Psychiatry, Warneford Hospital, Oxford
}

SUMMARY In a two-year study of patients admitted to hospital after deliberate self-poisoning or self-injury, a fivefold excess of patients with epilepsy was found compared with general population prevalence rates. Males with epilepsy were particularly over-represented. Patients with epilepsy were prone to make repeat attempts. Anticonvulsants, particularly barbiturates, were used in most cases of self-poisoning.

Several reports have indicated that people with epilepsy are at special risk of suicide, ${ }^{1-3}$ particularly those with temporal lobe epilepsy. ${ }^{4}$ Although a relationship between attempted suicide and epilepsy has been suggested previously, ${ }^{5-8}$ only Mackay ${ }^{9}$ has specifically studied this association. He found that $3.5 \%$ of a series of self-poisoning patients had epilepsy.

In a previous study of referrals to a general hospital after deliberate self-poisoning or selfinjury, ${ }^{10}$ an unexpectedly large number of patients with epilepsy was noted. A prospective study of referrals during two further years was, therefore, carried out in order to compare the rates for epilepsy in the attempted suicide population with those from the general population, and to compare the characteristics of epileptic and nonepileptic suicide attempters.

\section{Method}

During a two-year period, 1976-1977, data were collected for all cases of deliberate self-poisoning and self-injury admitted to the general hospital in Oxford and referred to the psychiatric consultation service. Ninety-six per cent of such admissions were referred to the service. Members of the clinical team completed a specially designed data sheet for each patient. On this was recorded demographic and clinical information, including whether or not the patient currently had epilepsy.

Rates for epilepsy were computed using the

Address for reprint requests: Dr $\mathbf{K}$ Hawton, Department of Psychiatry Warneford Hospital, Oxford OX3 7JX.

Accepted 22 June 1979 total referred population of attempters as the denominator. For the purpose of comparison with general population rates, those reported by Pond et $a l^{11}$ were used. These were based on a survey of patients registered with 14 general practitioners.

The demographic and clinical characteristics of the patients with epilepsy were compared with those of the rest of the non-epileptic patients admitted to hospital during the study period after self-poisoning or self-injury.

\section{Results}

During the study period, 42 patients with epilepsy were involved in 56 attempts. The rates of epilepsy per 1000 attempters are shown by sex for the two one-year periods in the table. The rate averaged over the two years, of 32.5 per 1000 attempters, is considerably in excess of general population prevalence rates. Thus, Pond et al ${ }^{11}$ reported a prevalence rate of $6 \cdot 2$ per 1000 . The rate of epilepsy among men attempters was approximately double that for women, whereas Pond and colleagues reported almost identical general population rates of epilepsy for the two sexes.

Table Numbers of attempted suicide patients with epilepsy and rates/1000 attempters (by sex)

\begin{tabular}{llll}
\hline & $\begin{array}{l}\text { Number of people } \\
\text { with epilepsy }\end{array}$ & $\begin{array}{l}\text { Total number of } \\
\text { attempters }\end{array}$ & $\begin{array}{l}\text { Rate of epilepsy } \\
\text { per } 1000 \\
\text { attempters }\end{array}$ \\
\hline Men & 21 & 402 & $52 \cdot 2$ \\
Women & 21 & 889 & 23.6 \\
Total & 42 & 1291 & $32 \cdot 5$ \\
\hline
\end{tabular}


The age distribution of the attempters with epilepsy was very similar to that of other attempters, with $60 \%$ aged under 30 years. However, $60 \%$ had a history of psychiatric treatment compared with $40 \%$ of other attempters $\left(\chi^{2}=9 \cdot 79\right.$, $\mathrm{p}<0.01$ ).

There were indications that the patients with epilepsy more often made repeat attempts. Thus $74 \%$ were known to have made previous attempts compared with $39 \%$ of other attempters $\left(x^{2}=\right.$ $17 \cdot 18, \mathrm{p}<0.001)$. Of those admitted in 1976, 10 $(56 \%)$ were referred to the same hospital after repeat attempts within a year of their first attempt in the study period compared with $14 \%$ of other attempters $\left(\chi^{2}=20.66, p<0.001\right)$. One male patient with epilepsy made eight attempts within this period.

Eighty-four per cent of attempts involved selfpoisoning, $13 \%$ self-injury, and $4 \%$ both methods. A similar distribution of methods was found in the general population of attempters. In $65 \%$ of cases of self-poisoning by patients with epilepsy, anticonvulsants were consumed, and in $60 \%$ of these the anticonvulsant was a barbiturate, usually phenobarbitone.

Alcohol was known to have been consumed within six hours of $59 \%$ of the attempts by patients with epilepsy and at the actual time in $41 \%$. These figures are in excess of those of $37 \%$ $\left(\chi^{2}=4.66, \mathrm{p}<0.05\right)$ and $21 \%\left(\chi^{2}=4.59, \mathrm{p}<0.05\right)$ respectively for all attempters.

Fifty-six per cent of the men with epilepsy and $40 \%$ of the women were known to be unemployed at the time of their attempts. These are considerably more than the respective figures of $27 \%$ $\left(x^{2}=5.31, \mathrm{p}<0.05\right)$ and $14 \%\left(\chi^{2}=9.05, \mathrm{p}<0.01\right)$ for the total populations of male and female attempters.

\section{Discussion}

A fivefold excess of patients with epilepsy has been found among attempted suicides compared with general population prevalence rates of epilepsy. This is likely to be an underestimate because of under-reporting of epilepsy, including concealment by patients. Nevertheless, it is remarkably similar to the rate reported by Mackay ${ }^{9}$ from Glasgow. It is clear that there is a significant association between epilepsy and attempted suicide. This may be explained by the wellrecognised risk of depression in patients with epilepsy. ${ }^{12}$

In this study one particularly problematical group of patients with epilepsy has been ident- ified. They frequently had histories of previous attempts and often went on to make repeat attempts. In addition they were characterised by a high rate of unemployment.

That men with epilepsy should be particularly over-represented is of interest. It has been suggested that the young male with epilepsy is especially handicapped, in a social sense, by his disorder. ${ }^{11}{ }^{13}$ An extremely large proportion of the men with epilepsy in this study were unemployed and most of them had previously received psychiatric treatment.

The frequent use of anticonvulsant drugs in self-poisoning by these patients presumably reflects availability. Barbiturate prescribing in general has been reduced and hence dangerous barbiturate poisoning has become far less frequent. ${ }^{14}$ However, barbiturate anticonvulsants were frequently used in overdoses by the patients with epilepsy in this study, often in combination with alcohol. This, together with the increased risk of depression and suicidal behaviour in epilepsy, highlights the necessity for both keeping a watch for depressive symptoms in patients with epilepsy and ensuring that their supply of drugs is kept within reasonable limits. It also supports the argument against the continued prescribing of barbiturates, which may themselves cause depression, when less hazardous alternatives are available for treating epilepsy.

\section{References}

1 Prudhomme C. Epilepsy and suicide. J Nerv Ment Dis 1941; 94:722-31.

2 Zielínski JJ. Epilepsy and mortality rate and cause of death. Epilepsia 1974; 15:191-201.

3 Bouchard G. Behavioural and psychiatric problems in epilepsy. In: Sweet $\mathbf{H}$, Obrador S, Martin-Rodriguez JG, eds. Neurosurgical Treatment in Psychiatry. Baltimore: University Park Press, 1977.

4 Taylor DC, Falconer MA. Clinical, sosicesonomic, and psychological changes after temporal lobectomy for epilepsy. $\mathrm{Br} J$ Psychiatry 1968; 114:1247-61.

5 Harrington JA, Cross KW. Cases of attempted suicide admitted to a general hospital. $\mathrm{Br}$ Med J 1959; 2:463-7.

6 Sclare HB, Hamilton CM. Attempted suicide in Glasgow. Br J Psychiatry 1963; 109:609-15.

7 Kessel N. Self-poisoning - part I. Br Med J 1965; 2:1265-70.

8 Lawson AAH, Mitchell I. Patients with acute poisoning seen in a general medical unit (1960-71). Br Med J 1972; 4:153-6.

9 Mackay A. Self-poisoning-a complication of epilepsy. Br J Psychiatry 1979; 134:277-82. 
10 Bancroft JH, Skrimshire AM, Reynolds F, Simkin S, Smith J. Self-poisoning and selfinjury in the Oxford area: epidemiological aspects 1969-73. Br J Prev Soc Med 1975; 29:170-7.

11 Pond DA, Bidwell BH, Stein L. A survey of epilepsy in 14 general practices: demographic and medical data. Psychiatr, Neurolog, Neurochir 1960; 63:217-36.
12 Betts TA, Merskey H, Pond DA. Psychiatry. In: Laidlaw J, Richens A, eds. A Textbook of Epilepsy. London: Churchill Livingstone, 1976.

13 Pond DA, Bidwell BH.A survey of epilepsy in 14 general practices: social and psychological aspects. Epilepsia 1960; 1:285-299..

14 Proudfoot AT, Park J. Changing pattern of drugs used for self-poisoning. Br Med J 1978; 1:90-3. 